\title{
SISTEM INFORMASI PENJUALAN UNTUK AL-FARIZI COMPUTER PALANGKA RAYA DENGAN ZACHMAN FRAMEWORK
}

\author{
${ }^{1}$ Sherly Jayanti, ${ }^{2}$ Ferdiyani Haris \\ ${ }^{1}$ Manajemen Informatika, ${ }^{2}$ Sistem Informasi - STMIK Palangkaraya \\ Jl. G. Obos No. 114 Palangkaraya, Kalimantan Tengah \\ E-mail : ' 1 sherlyjayanti85@yahoo.co.id, ${ }^{2}$ sabila006@gmail.com
}

\begin{abstract}
ABSTRAK
Perkembangan komputer sekarang ini sangat pesat dan digunakan diberbagai bidang kehidupan. Biasanya komputer digunakan untuk menghasilkan berbagai informasi penting guna meningkatkan kinerja dari organisasi, perusahaan atau lembaga agar pekerjaan yang dilakukan lebih efektif dan efisien hal ini disebabkan komputer melakukan proses informasi yang cepat. Untuk menjaga kelancaran, memantau dan juga mempermudah tugas pengelolaan data maka hal ini perlu dibuat sebuah sistem pengelolaan data pada Al-Farizi Computer Palangka Raya yang menyediakan perangkat keras komputer dan perangkat lunak untuk memenuhi kebutuhan pelanggan. Pengembangan arsitektur sistem informasi menggunakan Zachman Framework yang didukung dengan Microsoft SQL Server untuk database, interface dengan Microsoft Visual Basic, dan UML (Unified Modelling Language) untuk penggambaran model sistem informasi penjualan. Sistem informasi yang dihasilkan bisa memberikan informasi yang cepat dan akurat serta semakin membantu pelanggan mendapatkan yang tercocok dengan semakin cepat dan baik.
\end{abstract}

Kata Kunci : Sistem Informasi, Zachman Framework

\section{Pendahuluan}

Hal intuisi masih sangat susah dirumuskan karena berkaitan dengan knowledge, yaitu kemampuan sesuatu atau seseorang dalam menggunakan atau memanfaatkan sesuatu ilmu pengetahuan atau alat/teknologi untuk menghasilkan sesuatu atau menyelesaikan sesuatu. Tetapi sistem informasi yang baik yang bisa menyediakan informasi yang berkualitas kepada manajemen untuk membuat keputusan juga berperan bisa membantu memperpanjang hidup perusahaan dan peningkatan perkembangan perusahaan dalam persaingan yang semakin ketat dalam dunia perdagangan baik eceran maupun distribusi. Transaksi penjualan tidak selesai hanya pada tahap dimana barang diserahkan dan dibayar. Tetapi penerima barang, yaitu pelanggan merasa senang karena barang yang dibeli itu berguna baik untuk menyelesaikan permasalahan maupun memenuhi kebutuhan. Tetapi sekarang, brand yang besar telah menentukan harga jual kepada pelanggan dengan melakukan pertimbangan dari hasil survei dan penelitian lainnya dari masing-masing brand.

Semua ini bisa terjadi dan akan semakin baik jika ditopang dengan sistem informasi yang bisa mendukung penjualan dengan baik. Karena dengan adanya sistem informasi yang bisa memberikan informasi yang cepat dan akurat, maka Al-Farizi Computer Palangka Raya akan semakin bisa membantu pelanggan mendapatkan yang tercocok dengan semakin cepat dan baik.
Oleh karena itu, peneliti akan mengembangkan sistem informasi yang bisa menyediakan informasi dengan cepat dan gampang di akses agar pelayanan dan pemberian informasi ke konsumen bisa lebih cepat dilakukan supaya konsumen yang dilayani bisa lebih banyak dalam satu waktu.

\section{Kajian Teori}

\section{A. Sistem Informasi}

Sistem informasi dapat didefinisikan secara teknis sebagai kumpulan elemen-elemen yang saling berhubungan dan bekerjasama mengumpulkan, memproses, menyimpan, dan menyebarkan informasi yang mendukung pengambilan keputusan dan koordinasi dalam suatu organisasi. Selain mendukung pengambilan keputusan, koordinasi dan pengendalian, sistem informasi juga dapat membantu manajer dan pekerja menganalisa masalah, dan visualisasi dalam organisasi.

\section{B. Arsitektur Zachman Framework}

Adapun alat bantu yang dipakai untuk membangun arsitektur sistem informasi penjualan dalam penelitian ini adalah Zachman Framework, dimana Zachman Framework adalah sebuah ontologi. Sebuah teori tentang keberadaan seperangkat komponen penting yang terstruktur dari sebuah objek yang dimana diperlukan dan mungkin untuk membuat, mengoperasi, dan merubah objek tersebut (objek yang dimaksud 
bisa sebuah enterprise, sebuah departemen, sebuah solusi, sebuah projek, dan sebagainya). Zachman Framework bukan sebuah metodologi untuk menciptakan pelaksaaan dari sebuah objek.

Dengan meningkatnya ukuran dan kompleksitas dari implementasi sistem informasi, diperlukan penggunaan susunan logikal (arsitektur) untuk mendefinisikan dan mengontrol interface dan integrasi dari semua komponen dari sistem.

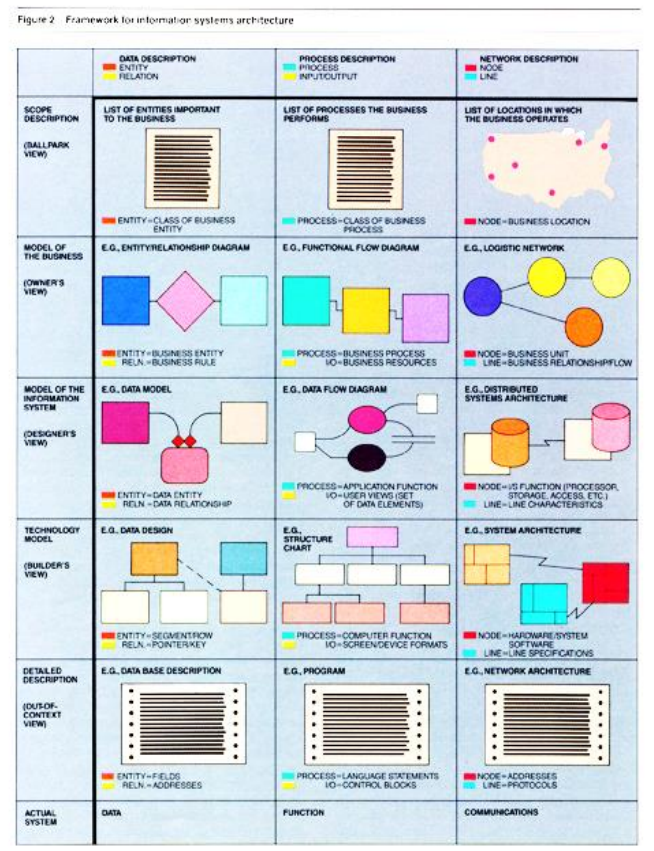

Gambar 1. Framework Arsitektur Sistem Informasi

Adapun penggambaran tools yang dipakai untuk membantu pembuatan arsitektur sistem informasi penjualan dengan Zachman Framework digambarkan sebagai berikut :

\begin{tabular}{|c|c|c|c|}
\hline $\begin{array}{c}\text { Zachman } \\
\text { Framework }\end{array}$ & Data (What) & Function (How) & Network (Where) \\
\hline $\begin{array}{c}\text { objectives' } \\
\text { Scope Model }\end{array}$ & $\begin{array}{l}\text { Data-data yang diperlukan } \\
\text { pada sistem dan entitas bisnis }\end{array}$ & $\begin{array}{l}\text { semua proses/fungsi yang } \\
\text { dipertukan sistem }\end{array}$ & deskripsi lokasi \\
\hline $\begin{array}{c}\text { model of the } \\
\text { business }\end{array}$ & $\begin{array}{l}\text { Diagram Relasi Entitas Bisnis } \\
\text { (Visio) }\end{array}$ & Use Case Diagram (UML) & lokasi implementasi \\
\hline $\begin{array}{c}\text { model of } \\
\text { information } \\
\text { system }\end{array}$ & Class Diagram (UML) & Activity Diagram (UML) & $\begin{array}{l}\text { Sequence Diagram } \\
\text { (UML) }\end{array}$ \\
\hline $\begin{array}{c}\text { technology } \\
\text { model }\end{array}$ & $\begin{array}{l}\text { Rancangan database dan } \\
\text { relasinya (MS SQL-Server) }\end{array}$ & \begin{tabular}{|} 
Disain interface \\
saftware(Visual Basic)
\end{tabular} & $\begin{array}{l}\text { Jaringan Komputer dengan } \\
\text { Virtual LAN } \\
\text { memanfaatkan hardware }\end{array}$ \\
\hline $\begin{array}{c}\text { representation } \\
\text { detail }\end{array}$ & $\begin{array}{l}\text { Data Definition (SQL- } \\
\text { server)/Rincian Karmus Data }\end{array}$ & $\begin{array}{l}\text { Program Aplikasi dari Visual } \\
\text { Basic }\end{array}$ & \begin{tabular}{|l|} 
Arsitektur dan Teknologi \\
Jaringan Komputer
\end{tabular} \\
\hline
\end{tabular}

Gambar 2. Zachman Framework untuk Arsitektur Sistem Informasi dengan tools yang dipakai dalam penulisan

\section{Implementasi}

Sistem yang dirancang akan dilakukan implementasi pada Al-Farizi Computer Palangka Raya, berikut ini adalah rincian implementasinya : A. Scope Model (Baris 1)
1) Entitas Bisnis (what)

Ruang lingkup data pada hasil kajian pengembangan tidak terjadi perubahan yaitu dengan entitas bisnis : Manager, administrator, sales/marketing dan pelanggan.

2) Fungsi-fungsi (How)

Proses-proses utama pada sistem informasi penjualan Al-Farizi Computer Palangka Raya :

a. Pendataan barang dagangan masuk yaitu barang yang masuk dicek sesuai dengan invoice masuk dan diberikan ke bagian administrasi yang berakibat penambahan stock barang dengan menginput ke program aplikasi.

b. Pendataan sales/marketing yaitu akan dicatat sebagai pengguna sistem yang bisa memasukkan data penjualan untuk setiap transaksi yang berhasil dilakukan yang berakibat pengurangan jumlah stock barang serta penambahan point komisi.

c. Penyerahan barang ke konsumen dengan pilihan cara :

1. Penyerahan langsung ketika terjadi transaksi

2. Barang diantar ke tujuan secara langsung

d. Barang dikirim melalui expedisi dengan menerbitkan surat jalan atau resi pengirimanPenerbitan surat piutang untuk transaksi pembayaran kredit.

e. Penerimaan pelunasan piutang dengan menerbitkan tanda lunas.

f. Penetapan harga jual dan besarnya komisi untuk setiap barang dagangan yang ada oleh manager sebagai super use.

g. Manager bisa melakukan input data barang dagangan inden untuk bisa dijual oleh sales/marketing dengan cara barang harus dipesan dulu.

h. Pendataan barang dagangan yang bisa diinden yang di tentukan oleh manager untuk didata oleh bagian administrasi.

i. Pelaporan meliputi :

1. Pencetakan laporan penjualan perperiode tertentu, bisa juga dengan persales dalam periode tertentu dengan point komisi.

2. Pencetakan laporan penjualan berdasar tipe barang atau merek tertentu.

3) Model Lokasi (Where)

Lokasi pengembangan dan implementasi hanya berada pada Al-Farizi Computer Palangka Raya yang terletak di provinsi Kalimantan Tengah, Palangka Raya.

B. Business Model (Baris 2)

1) Diagram Relasi Entitas Bisnis (What) 


$$
\begin{array}{r|l}
\text { Jurnal Sains Komputer dan Teknologi Informasi } & \text { Page } \\
\text { e-issn: 2655-7460. Volume } 2 \text { No.1, November 2019 } & 46-50
\end{array}
$$

Dalam relasi entitas bisnis yang dikembangkan terdapat relasi-relasi sebagai berikut :

a. Bagian admin memasukkan: data-data barang masuk sebagai acuan barang yang bisa dijual dan tersedia.

b. Manager menentukan harga jual dan komisi atas barang yang akan dijual. Manager mempunyai data supplier yang bisa dipakai untuk memberikan data barang yang bisa dijual dengan status inden. Manager memasukkan data barang tersebut sebagai data barang yang bisa dijual dengan status inden.

c. Sales/marketing menggunakan data barang untuk ditawarkan kepada calon pembeli yang potensional. Setelah melakukan penjualan, akan dimasukkan data barang terjual.

d. Calon pembeli atau pembeli meminta informasi spesifikasi dan harga barang.

2) Use Class Diagram (How)

Penggambaran proses-proses utama dengan use case diagram. Adapun gambarannya :

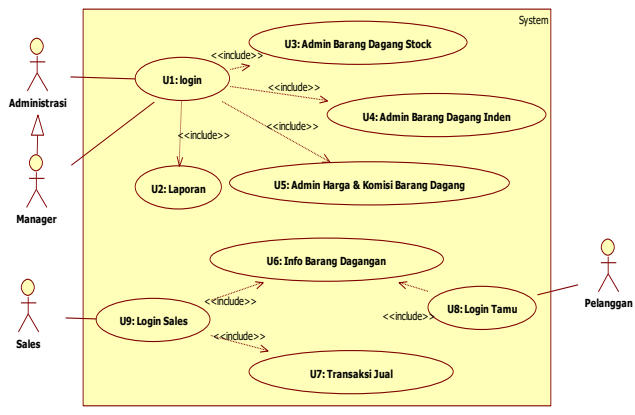

Gambar 3. Use Case Sistem Informasi Penjualan

3) Lokasi Kajian (Where)

Al-Farizi Computer Palangka Raya yang terletak di Provinsi Kalimantan Tengah, Indonesia akan menjadi tempat implementasi hasil pengembangan dari sistem informasi penjualan.

\section{System Information Model (Baris 3)}

1) Class Diagram (What)

Pada Class Diagram menjelaskan penggambaran Sistem Informasi Penjualan yang akan digunakan dengan bentuk hubungan setiap class dengan class yang lain. Hasil dari penggambaran class diagram ini akan diterapkan pada perancangan database aplikasi nantinya.

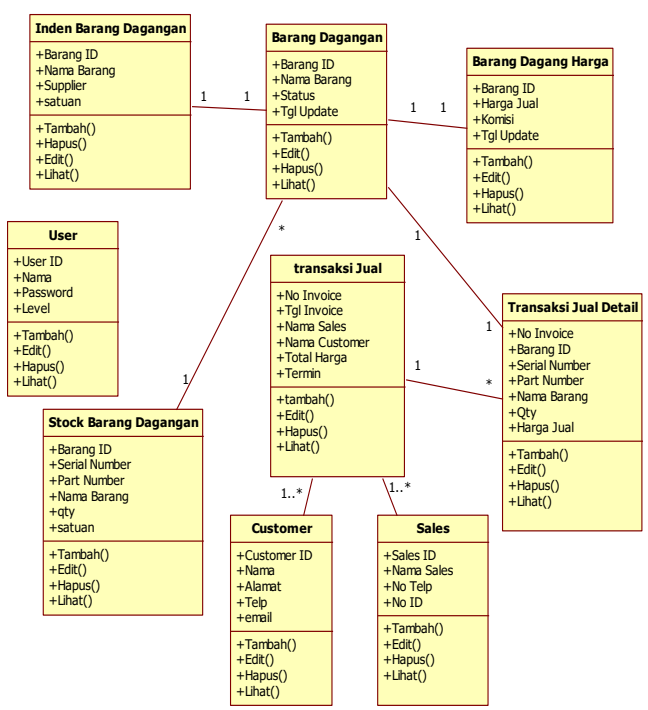

Gambar 4. Class Diagram

2) Activity Diagram (How)

System Information Model memaparkan alur dari setiap proses yang terjadi dijabarkan secara rinci dengan activity diagram yang menjelaskan setiap use case sebelumnya.

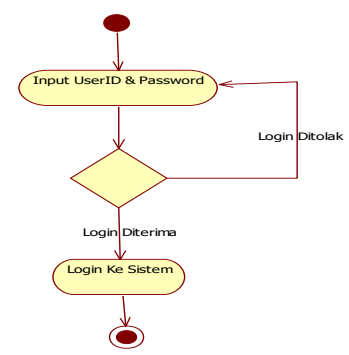

Gambar 5. Activity Diagram U1: Login

3) Sequence Diagram (Where)

Pada bagian ini akan digambarkan model sistem dengan sequence diagram adalah sebagai berikut :

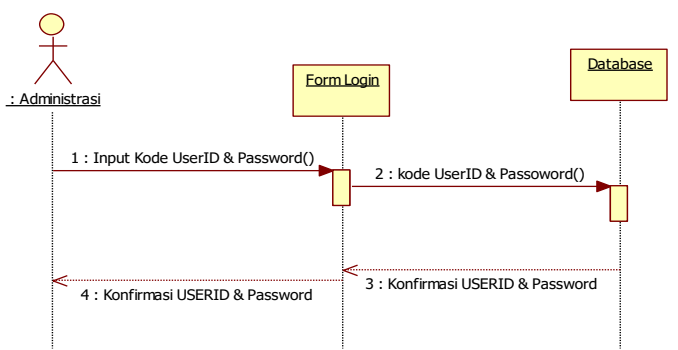

Gambar 6. Sequence Diagram U1: Login

D. Technology Model (Baris 4)

1) Database Design (What)

Database dikembangkan dengan Microsoft SQL server. Gambar dibawah adalah gambaran database dan relasi antar tabelnya. Tabel yang 
berhubungan mempunyai kunci utama dan kunci tamu.

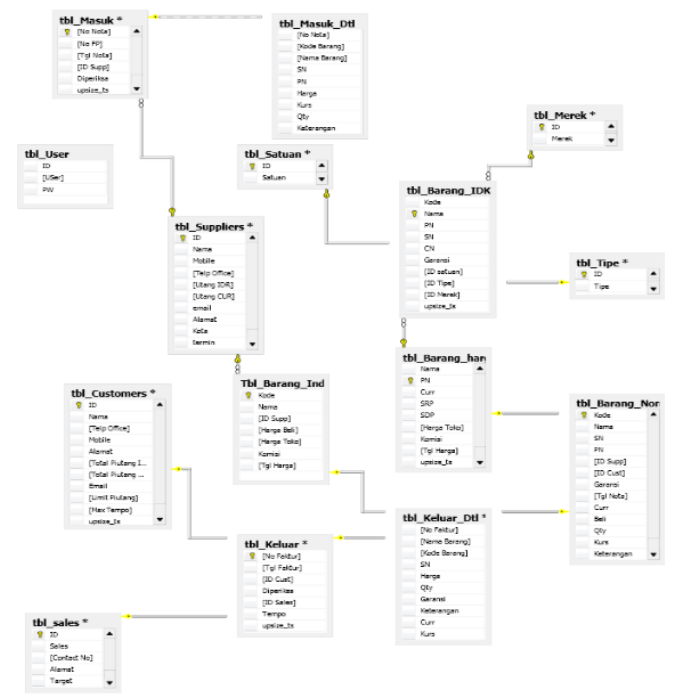

Gambar 7. Tabel pada SQL server dan relasinya

2) Interface (How)

Interface digambarkan dengan bantuan program Microsoft Visual Basic. Berikut adalah gambar interface login awal sistem :

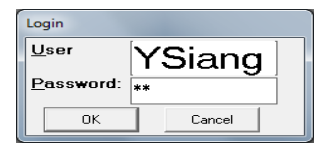

Gambar 8. Form Login Awal

3) Pemilihan Teknologi Hardware (Where)

Program aplikasi dikembangkan dengan bantuan tool visual basic 6, dan diperlukan komputer yang bisa mensupport sistem operasi windows yang ada. Program aplikasi akan diakses oleh multiple user, dimana harus terdapat sistem keamanan dalam mengakses data maupun sistem komputer itu sendiri, juga memanfaatkan sistem operasi windows server dengan dukungan client windows profesional.

\section{E. Detail Representation (Baris 5)}

1) Data Definition Language (What)

Pada bagian ini dipaparkan Data Definition Language dari Microsoft SQL Server untuk setiap tabel.

\section{2) Program Aplikasi (How)}

Program aplikasi ketika pertama kali dijalankan akan meminta user memasukkan userID dan password. Otentifikasi dilakukan dan otoritas diberikan sesuai dengan otoritas yang telah diatur. Sesudah itu akan muncul menu utama seperti gambar berikut :

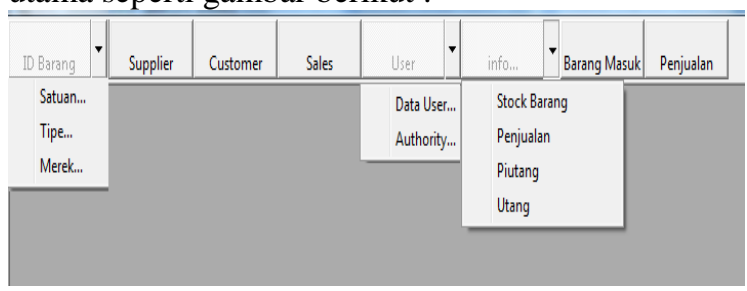

Gambar 8. Gambar tampilan menu awal program aplikasi

\section{3) Arstitektur Teknologi Jaringan Komputer (Where)}

Sebuah jaringan komputer lokal (LAN) diperlukan dengan menggunakan media transmisi kabel UTP dan wireless. Dan protokol yang dipakai adalah protokol TCP/IP dengan pengontrolan hak akses dengan memanfaatkan teknologi dari Microsoft Windows Server.

\section{Kesimpulan}

A. Telah dapat dihasilkan sistem informasi penjualan pada Al-Farizi Computer Palangka Raya menggunakan Zachman Framework, yaitu : Baris pertama yaitu baris Scope, Baris kedua menggambarkan Business Model, Baris ketiga, yaitu System Information Model, Untuk menggambarkan Technology Model pada baris ke-4, kolom what akan digambarkan rancangan database dengan bantuan tools program aplikasi Microsoft SQL dan Pada bagian terakhir atau baris ke lima yaitu Detail Representation, kolom what berisi gambaran detil dari tabel-tabel yang dipakai dalam database yang di gambarkan dengan DDL dari Microsoft SQL-Server.

B. Sistem yang dikembangkan ini dibuat dengan tampilan yang mudah digunakan dan dioperasikan baik bagi admin atau pengguna.

\section{Daftar Pustaka}

Arikunto, Suharsimi. 2007. Manajemen Penelitian, Rineka Cipta, Jakarta.

Haris, Ferdiyani. 2018. Rancang Bangun Aplikasi Ensiklopedia Berbasis Android. Jurnal Sains Komputer dan Teknologi Informasi. Vol 1 Issue 1 e-ISSN 2655-7460. https://doi.org/10.33084/jsakti.v1i1.448

Jogiyanto. 2005. Analisis dan Desain Sistem Informasi, Andi, Yogyakarta.

Mcleod, Raymond. 2001. Sistem Informasi Manajemen. Edisi ke-tujuh : jilid 1. PT. Prenhallindo, Jakarta. 


$$
\begin{array}{r|l}
\text { Jurnal Sains Komputer dan Teknologi Informasi } & \text { Page } \\
\text { e-issn: 2655-7460. Volume } 2 \text { No.1, November 2019 } & 46-50
\end{array}
$$

Mulyadi. 2001. Sistem Akuntansi. Edisi ke-tiga. Salemba 4, Jakarta.

Sam'ani. Annisa, S., Heri., 2018. Rancang Bangun Aplikasi Pengawasan Dan Pengendalian Komputer Laboratorium Multimedia STMIK Palangkaraya. Jurnal Sains Komputer dan Teknologi Informasi. Vol 1 Issue 1 e-ISSN 2655-7460. https://doi.org/10.33084/jsakti.v1i1.548

Septian Gugun., 2011. Trik Pintar Menguasai CodeIgniter. Jakarta : PT Alex Media Komputindo.

Sadeli, Muhammad. 2011. 7 Jam Belajar Interaktif Dreamweaver CS5 untuk Orang Awam. Maxikom : Palembang.

Sugiyono. 2011. Metode Penelitian Kuantitatif Kualitatif dan $R \& D$. Alfabeta : Bandung.

Turban, Efraim, R.Kelly Rainer, and Richard E. Potter. 2005. Introduction to Information Technology. Wiley : United States of America. 